\title{
Identification of phenolic compounds from medicinal and mellif- erous plants and their cytotoxic activity in cancer cells
}

\author{
Alesiani ${ }^{1}$ Daniela, Elena Pichichero ${ }^{1}$, Lorena Canuti ${ }^{1}$, Rosella Cicconi $^{1}$, Damintoti \\ Karou $^{2}$, Giuseppe D’Arcangelo ${ }^{3}$ and Antonella Canini ${ }^{*}, 1$ \\ ${ }^{1}$ Department of Biology and ${ }^{3}$ Department of Sciences and Chemical Technologies, University of Rome "Tor Ver- \\ gata", Via della Ricerca Scientifica, 1- 00133 Rome, Italy. \\ ${ }^{2}$ Laboratoire de Biologie Médicale Saint Camille de Ouagadougou, 01 BP 364 Ouagadougou 01, Burkina Faso.
}

\begin{abstract}
The aim of this work is to carry out a phytochemical analysis and biological screenings of vegetable extracts from Sida acuta and Malva sylvestris leaves, Castanea sativa and Eucalyptus camaldulensis pollen. Chemical analyses was focused on secondary metabolites, particularly phenolic compounds, which have several roles in the plant physiological processes and had demonstrated significant capacity in the prevention and care of human health diseases. Solid phase extraction (SPE) and analyses with liquid chromatography and mass spectrometry (HPLC-MS) allowed the identification of 5,7-dimethoxycoumarin, kaempferol, quercetin, genistein, apigenin and myricetin. Moreover, the M. sylvestris and S. acuta extracts demonstrated a cytotoxic activity on murine and human cancer cell lines by using a MTT assay.
\end{abstract}

Key words: antineoplastic activity, phenolic compounds, phytochemical analysis, plant extracts.

\section{INTRODUCTION}

The plants are used in the treatment of human diseases all the time. From the last century, a scientific interest for phytotherapy increased in several medical fields such as immunology, oncology, haematology and the use of plants in medicine has affected the identification of natural compounds: cocaine, morphine, vinblastine, taxolo, codeine are some examples (BALUnAS and Kinghorn 2005).

The aim of this work is to carry out a phytochemical analysis of vegetable extracts and their secondary metabolites, particularly phenolic compounds. These molecules have several roles in the plant physiological processes, as protection from UV, defense against pathogens and phytophagous, pollination and dissemination, symbiosis and allelopathic interactions (BUCHANAN et al. 2000). Epidemiological evidences have supported the role that intake of antioxidants, including phenolic compounds, plays in the prevention of several chronic diseases such as cardiovascular disease, cancer, diabetes, bacterial and parasitic in-

\footnotetext{
* Corresponding author: phone +39 06-72594344; fax +39 06-2023500; e-mail: canini@uniroma2.it
}

fections (Murakami et al. 1994; Sherman and Billing 1999). Two medicinal plants, Sida acuta Burm. F. (Malvaceae) and Malva sylvestris L. (Malvaceae); and two melliferous plants, Castanea sativa Mill. (Fagaceae) and Eucalyptus camaldulensis Dehnh (Myrtaceae) were selected.

S. acuta is a shrub distributed in tropical regions of the world. In traditional medicine, the leaves are used in the care of asthma, renal inflammation, colds, fever, headache, ulcers, worms and malaria (Coee and Anderson 1996). Biological screenings have shown a significant antimalarial activity of plant extracts (KAROU et al. 2003); recently, cryptolepine and quindoline were identified in alkaloid extracts of the leaf (BAnzouzi et al. 2004; KAROu et al. 2005) and they are considered the major metabolites of the plant having antimalarial activity. M. sylvestris is an herbaceous plant used in phitotherapy and widely distributed in Italy (GUARRERA 2005): the leaves are used as emollient, laxative and cough medicine (Gonda et al. 1990). Terpenoids, phenolic acids and anthocyanins were identified in water leaf extract of the plant (Cutillo et al. 2006). C. sativa is an arboreal plant very common in Mediterranean scrub. Its leaf extracts contain a high level of total phenolic compounds and showed a significant antioxidant potential with antiproliferative activ- 
ity on B16 cells (CALListe et al. 2001; 2005) and an in vitro antibacterial effect. Moreover, the seeds of the plant are used in treatment of gastroenteritis and in coeliac disease; in the relative extracts, alkaloids have been identified (HIERMANN et al. 2002). E. camaldulensis is a tree indigenous of Australia and it is the species of Eucalyptus more common in Italy; antioxidant activity of its leaf extract are known (EL-GHorAB et al. 2003).

The high pressure liquid chromatographymass spectrometry (HPLC-MS) has been used to identify and to quantify the molecules in the plant extracts, obtained using the solid phase extraction (SPE). This extraction method allows to concentrate and to clean up the extracted sample before chromatographic injection, through the separation of interesting molecular classes from interferences of biological matrix.

Moreover, some analysed extracts have been screened about their antineoplastic activity on murine B16 melanoma and human A375 melanoma cell lines.

\section{MATERIALS AND METHODS}

Plant material - $300 \mathrm{~g}$ sample of Sida acuta L. (Malvaceae) from West Cameroun and of Malva sylvestris L. (Malvaceae) leaves from Italy were collected in March 2006; samples were collected and identified by Prof. A. Canini. A voucher specimen of this raw material is deposited at Herbarium of University of Rome "Tor Vergata". Moreover, pollen of Castanea sativa Mill. (Fagaceae) and Eucalyptus camaldulensis Dehnh (Myrtaceae) was collected in italian "Appia Antica" Park in May 2006.

Reagents - Standard reference compounds used for qualitative and quantitative analyses, as well as, methanol, hydrochloric acid $(\mathrm{HCl})$, trifluoroacetate (TFA) and formic acid were purchased from Sigma-Aldrich (St. Louis, MO, USA). The standard reference compounds are 5,7-dimethoxycoumarin, kaempferol (3,4',5,7-tetrahydroxyflavone), quercetin $\left(3,3^{\prime}, 4^{\prime}, 5,7\right.$-pentahydroxyflavone), genistein (4',5,7-trihydroxyisoflavone), apigenin (4',5,7-trihydroxyflavone) and myricetin (3,3',4',5,5',7-hexahydroxyflavone). All solvents and reagents used in this study were of analytical grade purity.

Extraction of phenolic compounds - The extraction of phenolic compounds from the leaves and pollen was carried out as follows. Plant material (10 g) was reduced to a fine powder and extracted in a Soxhlet extractor $\left(90^{\circ} \mathrm{C}\right.$ for $\left.24 \mathrm{~h}\right)$ with $200 \mathrm{ml}$ of $70 \%$ aqueous methanol $(\mathrm{v} / \mathrm{v})$ acidified to $\mathrm{pH} 2$ with some concentrated $\mathrm{HCl}$ drops.

The filtered extract was used for solid phase extraction of phenolic compounds. After methanol evaporation in a rotary evaporatory, the resulting aqueous solution was adjusted to $\mathrm{pH} 2$ and extracted using C-18 cartdrige (Sigma-Aldrich): the stationary phase of the column was conditioned with methanol and TFA $0,1 \%$, then the sample was transferred into the column and phenolic components were eluited with methanol solvent for chemical analyses.

Preparation of the standard solutions - Methanolic solutions of 5,7-dimethoxycoumarin, kaempferol, quercetin, genistein, apigenin and myricetin were prepared for qualitative and quantitative analyses of leaf extracts. In HPLC-APCI analyses, $5 \mu \mathrm{L}$ of each standard solution were injected in the column.

Analytical protocol - Chemical analyses were performed using an HPLC instrumentation (Waters), coupled to a mass spectrometry at triple-quadrupole model TSQ 7000 (Finnigan, U.S.A.). The HPLC was equipped with a Supelco C-18 column. In the mobil phase the solvent was $(\mathrm{A}) \mathrm{H}_{2} \mathrm{O}$ formic acid $(99,9: 0,1)$ and (B) methanol; it was set to a pressure of $1 \mathrm{ml} / \mathrm{min}$ and used in isocratic conditions as follows, solvent (A) 30\%, solvent (B) $70 \%$. The mass spectrometer was operated in APCI (atmospheric pressure chemical ionization) mode, detection was performed in scanning mode and peaks identified using target ions. For the samples analysed, the chromatogram peak identification was carried out with the comparison of the retention time ( $\mathrm{rt}$ ) and mass spectra of the compounds in the extract to those of analysed standards.

Cell culture - B16 (murine melanoma), A375 (human melanoma) and CHP100 (human neuroblastoma) cell lines were cultured in RPMI 1640 medium supplemented with $10 \%(\mathrm{v} / \mathrm{v})$ foetal bovine serum (FCS), 1\% L-glutamine (v/v), $100 \mathrm{U}$ penicillin and $100 \mu \mathrm{g} / \mathrm{ml}$ streptomycin. The cells were grown at $37^{\circ} \mathrm{C}$ in a humidified atmosphere with $5 \% \mathrm{CO}_{2}$.

MTT assay - Cytotoxicity of M. sylvestris and $S$. acuta extracts was estimated by 3-(4,5-dimethylthiazol-2-yl)-2,5-diphenyl tetrazolium bromide (MTT) assay. Cell suspensions $(100 \mu \mathrm{l})$ were 
seeded into sterile 96-well plates at a density of $1 \times 10^{3}$ cells/well for B16 and of $2 \times 10^{3}$ for A375 and CHP100; $100 \mu \mathrm{l}$ of methanolic solutions of extract were added in cellular culture media over the final dilutions. The plates were incubated in $5 \% \mathrm{CO}_{2}$ at $37^{\circ} \mathrm{C}$ for a period of 48 and $72 \mathrm{~h}$. After incubation time, cellular survival was determined according to the method described by MosmanN (1983).

\section{RESULTS AND DISCUSSION}

The standard solutions and the plant methanolic extracts were analyzed in HPLC and APCI scanning mode. For each standard molecule analysed, the relative retention time ( $\mathrm{rt}$ ) was obtained. In Table 1, the rt and the characteristic molecular ion for each compound are shown. The results of chemical analyses were compared with those of standard solutions analyses, as explained in the experimental section. For each plant extract, the secondary metabolites identified are shown in $\mathrm{Ta}$ ble 2: they are quercetin ( $\mathrm{rt} 2.94 \mathrm{~min}$ ), 5,7-dimethoxycoumarin (rt 3.04), kaempferol (rt $3.42 \mathrm{~min}$ ), apigenin ( $\mathrm{rt} 3.49 \mathrm{~min}$ ), myricetin ( $\mathrm{rt} 3.51 \mathrm{~min}$ ) and genistein (rt $3.90 \mathrm{~min}$ ). The 5,7-dimethoxycoumarin is a compound studied not much and few data are available on it, but it is a member of a very large class of molecules widely distributed in na-

Table 1 - Secondary metabolites analysed using HPLC-MS: for each, retention time obtained from chromatogram and molecular ion from mass spectrum are shown.

\begin{tabular}{|c|c|c|c|}
\hline Number & Compound & $\mathrm{rt}(\mathrm{min})$ & Molecular ion \\
\hline 1 & quercetin & 2.94 & 302 \\
\hline 2 & $\begin{array}{l}5,7 \text {-dimeth- } \\
\text { oxycoumarin }\end{array}$ & 3.04 & 206 \\
\hline 3 & kaempferol & 3.42 & 286 \\
\hline 4 & apigenin & 3.49 & 270 \\
\hline 5 & myricetin & 3.51 & 318 \\
\hline 6 & genistein & 3.90 & 271 \\
\hline
\end{tabular}

Table 2 - Identification of secondary metabolites in plant extracts analysed (l=leaf; $\mathrm{f}=$ flower; $\mathrm{p}=$ pollen).

\begin{tabular}{lccc}
\hline \multicolumn{1}{c}{ Compound } & M. sylvestris & C. sativa & Eucalyptus \\
\hline quercetin & $+(\mathrm{l})$ & - & $+(\mathrm{p})$ \\
5,7 -dimeth- & $+(\mathrm{l})$ & - & $+(\mathrm{p})$ \\
oxycoumarin & $+(\mathrm{l}, \mathrm{f})$ & - & $+(\mathrm{p})$ \\
kaempferol & $+(\mathrm{f})$ & - & $+(\mathrm{p})$ \\
apigenin & $+(\mathrm{l})$ & $+(\mathrm{p})$ & - \\
myricetin & $+(\mathrm{f})$ & - & - \\
genistein & & &
\end{tabular}

ture (EGAN et al. 1990). This coumarin was identified in some species, among which Euodia borbonica var. borbonica L. (VALENCIENNES et al. 1999), Citrus limon L. (Salvatore et al. 2004) and Citrus medica sarcodactylis (GAO et al. 2002). It is a phototoxic coumarin (SALVATORE et al. 2004); lately, some preliminary works about its anti-cancer activity have been carried out. (KAWAII et al. 1999). Kaempferol has antiviral (Mitrocotsa et al. 2000), antioxidant and antiprotozoic (CALZADA et al. 1999) activities; quercetin is the major flavonoid in the human diet and has been reported to exhibit antioxidative (CHOPRA et al. 2000), anticarcinogenic (PereIRA et al. 1996), anti-inflammatory (FERRY et al. 1996), antiaggregatory (Pignatelli et al. 2000) and vasodilating (Perez-Vizcaino et al. 2002) effects. Apigenin showed to possess antitumor and a strong antioxidant activities (CÁRDENAS et al. 2006), as well as genistein (JEUNE et al. 2005; RUFER and KulLing 2006) and myricetin (VALDEZ et al. 2004; MAGGiolini et al. 2005). In this work, for the first time, some of active compounds responsable of vegetable activity in animal models have been isolated and identified both in S. acuta and M. sylvestris. S. acuta extracts showed a cancer chemopreventive activity (JANG et al. 2003); M. sylvestris extracts are reported for their radical scavenging effect (El and Karakaya 2004) as well as E. camaldulensis and C. sativa; the later demonstrated also antineoplastic activity in B16 cells (CAlliste et al. 2001). Surely, the identified metabolites cooperate to these effects.

Fig. 1 shows the results of MTT assay by using Malva sylvestris extract. This extract showed a cytotoxic effect for B16 and A375 cell lines. In B16 cells, the extract showed an antiproliferative activity of $61 \%$ and $97 \%$ respect to the control for 1:200 and 1:40 dilution, respectively. For A375 cells, the 1:10 dilution produced a significant reduction of the cell proliferation, $58 \%$ respect to the control; the 1:40 dilution showed a lower effect with a reduction of $85 \%$. The biological assay showed, for the first time, that M. sylvestris extracts reduces proliferation of cancer cell lines. For B16 cells, the greater effetc is produced by 1:40 dilution in which the sample is more concentrated; instade, in A375 cells the lower concentartions analysed, 1:40, showed a major activity respect to $1: 10$. These data showed that each line reacts specifically to the same treatment, both the vegetable extracts and the methanol. S. acuta methanolic extract demonstrated, after $48 \mathrm{~h}$ incubation, a dose-dependent antiproliferative effect on CHP100 cells with a cell viability reduction of 
a)

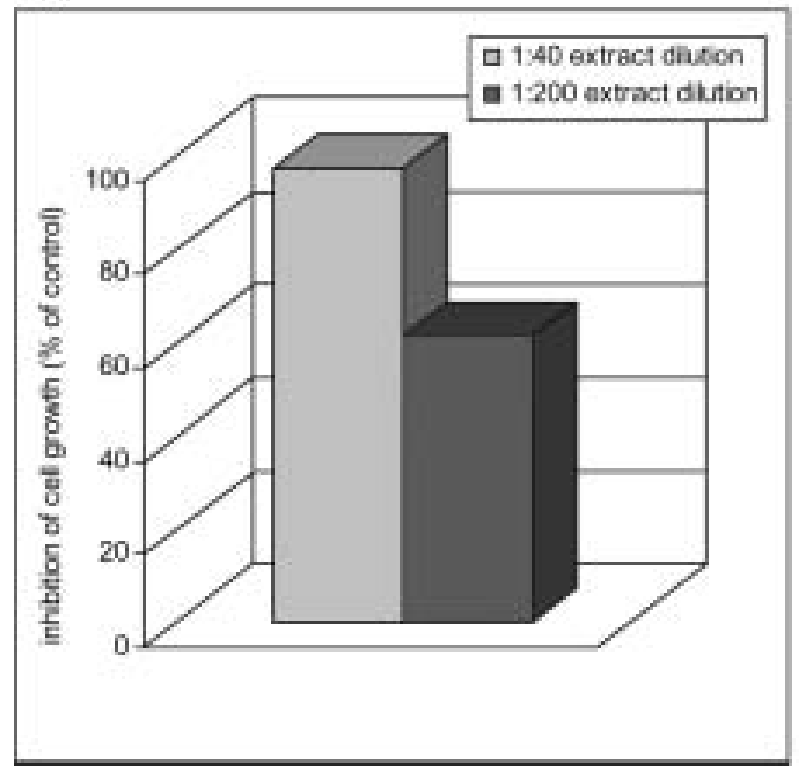

b)

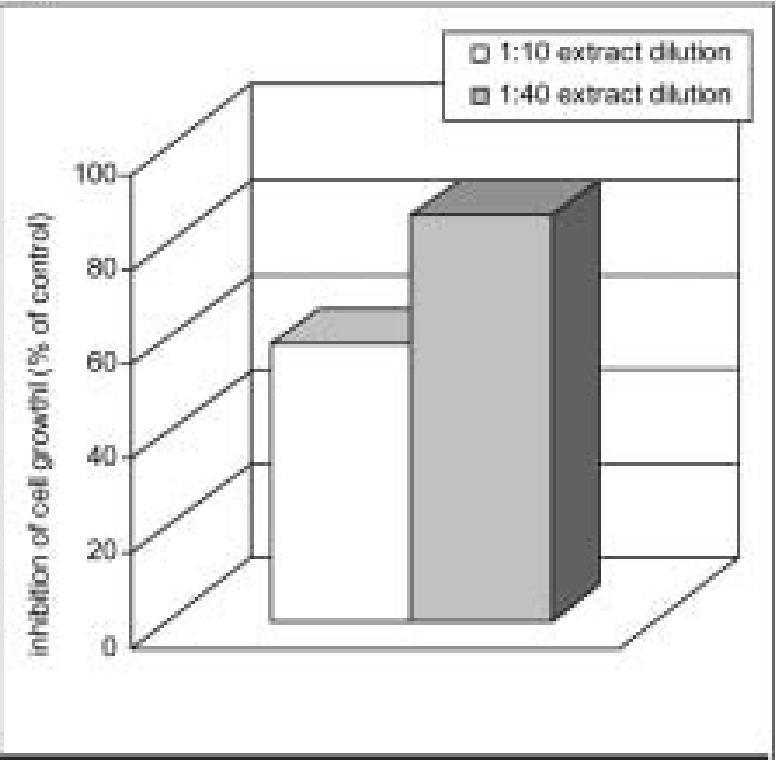

Fig. 1 - Antiproliferative activity of M. sylvestris extract in a) B16 and b) A375 cell lines as detected by the MTT assay. The cells were incubated with different concentrations of extract for $72 \mathrm{~h}$, as reperted in the section of Materials and Methods.

$7 \%, 9 \%, 20 \%$ and $82 \%$ for $0,1 \mu \mathrm{g} / \mathrm{ml}, 1 \mu \mathrm{g} / \mathrm{ml}$, $10 \mu \mathrm{g} / \mathrm{ml}$ and $50 \mu \mathrm{g} / \mathrm{ml}$, respectively (Fig. 2). For $S$. acuta, chemopreventive activity is shown in literature (JANG et al. 2003) and this preliminary in vitro experiment showed a cytotoxic activity of metabolites from plant extract in cancer cells, which after treatment reduced significatively cellular

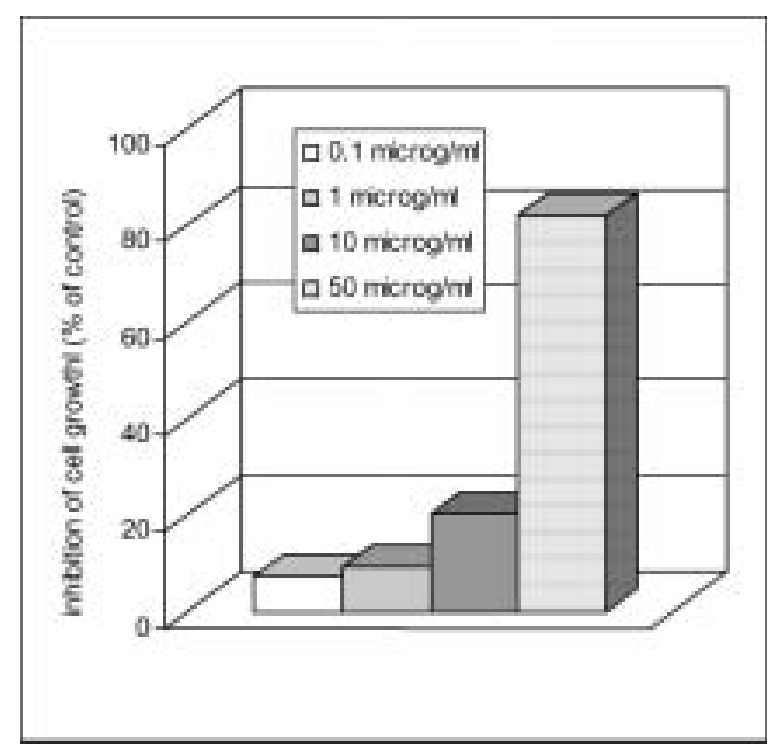

Fig. 2 - Antiproliferative activity of $S$. acuta methanolic extract in CHP100 cell line as detected by the MTT assay. The cells were incubated with different concentrations of extract for $72 \mathrm{~h}$, as reperted in the section of Materials and Methods. growth and survival. Further investigations are necessary to demonstrate an antineoplastic activity of the screened extracts and to understand the molecular mechanism triggered in the cell by them until the final antiproliferative result.

\section{REFERENCES}

Balunas M.J. and Kinghorn A.D., 2005 - Drug discovery from medicinal plants. Life Sciences, 78: 431441.

Banzouzi J.T., Prado R., Menan H., Valentin A., Roumestan C., Mallí́ M., Pelissier Y. and Blache Y., 2004 - Studies on medicinal plants of Ivory Coast: investigation of Sida acuta for in vitro antiplasmodial activities and identification of an active constituent. Phytomedicine, 11:338-341.

Buchanan B.B., Gruissem W. and Jones R.L., 2000 - Natural products (secondary metabolites). In American Society of Plant Biologists (Eds), "Biochemistry and molecular biology of plants", p. 1250-1309. Rockville, MD.

Calliste C.A., Trouillas P., Allais D.P. and Duroux J.L., 2005 - Castanea sativa Mill. leaves as new sources of natural antioxidant: an electronic spin resonance study. Journal of Agricultural and Food Chemistry, 53: 282-288.

Calliste C.A., Trouillas P., Allais D.P., Simon A. and Duroux J.L., 2001 - Free radical scavenging activities measured by electron spin resonance spectroscopy and B16 cell antiproliferative behaviors of 
seven plants. Journal of Agricultural and Food Chemistry, 49: 3321-3327.

Calzada F., Meckes M. and Cedillo-Rivera R., 1999 - Antiamoebic and antigiardial activity of plant flavonoids. Planta medica, 65: 78-80.

Cardenás M., Marder M., Blank V.C. and Roguin L.P., 2006 - Antitumor activity of some flavonoids and synthetic derivatives on various buman and murine cancer cell line. Bioorganic \& Medicinal Chemistry, 14: 2966-2971.

Chopra M., Fitzsimons P.E., Strain J.J., Thurnham D.I. and How ARD A.N., 2000 - Nonalcoholic red wine extract and quercetin inbibit LDL oxidation without affecting plasma antioxidant vitamin and carotenoid concentrations. Clinical Chemistry, 46: 1162-1170.

Coee F.G. and Anderson G.J., 1996 - Ethnobotany of the Garifuna of Eastern Nicaragua. Economic Botany, 50: 71-107.

Cutillo F., D’Abrosca B., Della Greca M., FiorenTINo A. and Zarrelli A., 2006 - Terpenoids and phenol derivatives from Malva sylvestris. Phytochemistry, 67: 481-485.

Egan D., O’Kennedy R., Moran E., Cox D., Prosser E. and Thornes R.D., 1990 - The pharmacology, metabolism, analysis, and applications of coumarin and coumarin-related compounds. Drug Metabolism Reviews, 22: 503-529.

EL S.N. and KARAKAyA S., 2004 - Radical scavenging and iron-chelating activities of some greens used as traditional dishes in Mediterranean diet. International Journal of Food Sciences and Nutrition, 55(1): 67-74.

El-Ghorab A.H., El-Massry K.F., Marx F. and FADEL H.M., 2003 - Antioxidant activity of Egyptian Eucalyptus camaldulensis var. brevirostris leaf extracts. Nahrung, 47(1): 41-45.

Ferry D.R., Smith A., Malkhandi J., Fyfe D.W., De Takats P.G., Anderson D. et al., 1996 Phase I clinical trial of the flavonoid quercetin: pharmacokinetics and evidence for in vivo tyrosine kinase inbibition. Clinical Cancer Research, 2: 659-668.

Gao Y., Huang H., Xu H., Diao Y. and Dong Z., 2002 - Studies on the chemical constituents of Citrus medica var. sarcodactylis. Zhong Yao Cai, 25: 639-640.

Gonda R., Tomoda M. and Shimizu N., 1990 - Structure and anticomplementary activity of an acidic polysaccharide from the leaves of Malva sylvestris var. mauritiana. Carbohydrate Research, 198: 323329.

GuARrera P.M., 2005 - Traditional phytotherapy in central Italy (Marche, Abruzzo, and Latium). Fitoterapia, 76: 1-25.

Hiermann A., Kedwani S., SchrammH.W. and Seger C., 2002 - A new pyrrole alkaloid from seeds of Castanea sativa. Fitoterapia, 73: 22-27.

Jang D.S., Park E.J., Kang Y.H., Su B.N., Hawthorne M.E., Vigo J.S., Graham J.G., Cabieses F., Fong H.H.S., Mehta R.G., Pezzuto J.M. and Kinghorn A.D., 2003 - Compounds obtained from
Sida acuta with the potential to induce quinone reductase and to inbibit 7,12-dimetbylbenz[a]anthracene-induced preneoplastic lesions in a mouse mammary organ culture model. Archives of Pharmacal Research, 26(8): 585-590.

Jeune M.A., Kumi-Diaka J. and Brown J., 2005 Anticancer activities of pomegranate extracts and genistein in buman breast cancer cells. Journal of Medicinal Food, 8(4): 469-475.

Karou D., Mamoudou H.D., Souleymane S., SimPORE J and Traore A.S., 2003 - Antimalarial activity of Sida acuta Burm. f. (Malvaceae) and Pterocarpus erinaceus Poir. (Fabaceae). Journal of Ethnopharmacology, 89: 291-294.

Karou D., Savadogo A., Canini A., Saydou Y., Montesano C., Simpore J., Colizzi V. and Traore A.S., 2005 - Antibacterial activity of alkaloids from Sida acuta. African Journal of Biotechnology, 4(12): 1452-1457.

Kawail S., Tomono Y., Katase E., Ogawa K. and YANO M., 1999 - Isolation of furocoumarins from bergamot fruits as HL-60 differentiation-inducing compounds. Journal of Agricultural and Food Chemistry, 47: 4073-4078.

Maggiolini M., Recchia A.G., Bonofiglio D., Catalano S., Vivacqua A., Carpino A., Rago V., Rossi R. and Andò S., 2005 - The red wine phenolics piceatannol and myricetin act as agonists for estrogen receptor a in buman breast cancer cells. Journal of Molecular Endocrinology, 35: 269-281.

Mitrocotsa D., Mitaku S., Axarlis S., Harvala C. and Malamas M., 2000 - Evaluation of the antiviral activity of kaempferol and its glycosides against buman cytomegalovirus. Planta Medica, 66: $377-$ 379.

Mosmann T., 1983 - Rapid colorimetric assay for cellular growth and survival: application to proliferation and cytotoxicity assays. Journal of Immunological Methods, 65: 55-63.

Murakami A., Ohigashi H. and Koshimizu K., 1994 - Possible anti-tumor promoting properties of traditional Thai foods and some of their active constituents. Asia Pacific Journal of Clinical Nutrition, 3: 185-191.

Pereira M.A., Grubbs C.J., Barnes L.H., Li H., Olson G.R. and Ето I., 1996 - Effects of the phytochemicals, curcumin and quercetin, upon azoxymethane-induced colon cancer and 7,12-dimetbylben$z$ [a]anthracene-induced mammary cancer in rats. Carcinogenesis, 17: 1305-1311.

Perez-Vizcaino F., Ibarra M., Cogolludo A.L., Duarte J., Zaragoza-Arnaez F., Moreno L. et al., 2002 - Endothelium-independent vasodilator effects of the flavonoid quercetin and its metbylated metabolites in rat conductance resistance arteries. Journal of Pharmacology and Experimental Therapeutics, 302: 66-72.

Pignatelli P., Pulcinelli F.M., Celestini A., Lenti L., Ghiselli, A., Gazzaniga P.P. et al., $2000-$ The flavonoids quercetin and catechin synergistically inhibit platelet function by antagonizing the intracel- 
lular production of bydrogen peroxide. American Journal of Clinical Nutrition, 72: 1150-1155.

Rufer C.E. and Kulling S.E., 2006 - Antioxidant activity of isoflavones and their major metabolites using different in vitro assays. Journal of Agriculture and Food Chemistry, 54: 2926-2931.

Salvatore A., Borkosky S., Willink E. and Bardòn A., 2004 - Toxic effects of lemon peel constituents on Ceratitis capitata. Journal of Chemical Ecology, 30: 323-333.

Sherman P.W. and Billing J., 1999 - Darwinian gastronomy: Why we use spices. Bioscience, 49: 453-463.
Valdez L.B., Alvarez S., Zaobornyj T. and Boveris A., 2004 - Polyphenols and red wine as antioxidants against peroxynitrite and other oxidants. Biological Research, 37(2): 279-286.

Valenciennes E., Smadja J. and Conan J.Y., 1999 Screening for biological activity and chemical composition of Euodia borbonica var. borbonica (Rutaceae), a medicinal plant in Reunion Island. Journal of Ethnopharmacology, 64: 283-288.

Received November 30 ${ }^{\text {th }}$ 2006; accepted January $30^{\text {th }} 2006$ 